\title{
REVIEW
}

\section{Role of extracellular proton-sensing OGR1 in regulation of insulin secretion and pancreatic $\beta$-cell functions}

\author{
Chihiro Mogi, Takashi Nakakura and Fumikazu Okajima \\ Laboratory of Signal Transduction, Institute for Molecular and Cellular Regulation, Gunma University, Maebashi 371-8512, Japan
}

\begin{abstract}
Insulin secretion with respect to $\mathrm{pH}$ environments has been investigated for a long time but its mechanism remains largely unknown. Extracellular $\mathrm{pH}$ is usually maintained at around 7.4 and, its change has been thought to occur in non-physiological situations. Acidification takes place under ischemic and inflammatory microenvironments, where stimulation of anaerobic glycolysis results in the production of lactic acid. In addition to ionotropic ion channels, such as transient receptor potential V1 (TRPV1) and acid-sensing ion channels (ASICs), metabotropic proton-sensing G proteincoupled receptors (GPCRs) have also been identified recently as proton-sensing machineries. While ionotropic ion channels usually sense strong acidic $\mathrm{pH}$, proton-sensing GPCRs sense $\mathrm{pH}$ of 7.6 to 6.0 and have been shown to mediate a variety of biological actions in neutral and mildly acidic $\mathrm{pH}$ environments. Studies with receptor knockout mice have revealed that proton-sensing receptors, including ovarian cancer G protein-coupled receptor 1 (OGR1), a proton-sensing GPCRs, play a role in the regulation of insulin secretion and glucose metabolism under physiological conditions. Small molecule 3,5-disubstituted isoxazoles have recently been identified as OGR1 agonists working at neutral $\mathrm{pH}$ and have been shown to stimulate pancreatic $\beta$-cell differentiation and insulin synthesis. Thus, proton-sensing OGR1 may be an important player for insulin secretion and a potential target for improving $\beta$-cell function.
\end{abstract}

Key words: Proton-sensing GPCRs, OGR1, Insulin secretion, Pancreatic $\beta$-cell

\section{Backgrounds: Glucose Metabolism and Insulin Secretion with Respect to $\mathbf{p H}$ Environments}

CIRCULATING BLOOD $\mathbf{p H}$ is strictly maintained at around 7.4 by respiratory and renal compensation mechanisms. Disorders that lower the arterial $\mathrm{pH}$ $<7.35$ are defined as acidosis, whereas disorders with a $\mathrm{pH}>7.45$ are termed alkalosis [1]. In 1975, Yajima and Ui reported that acidosis modifies basal and glucosestimulated insulin secretion in vivo $[2,3]$. Thus, when ammonium chloride was administered in rats, the procedure that is used for the induction of acidosis, basal and glucose-stimulated insulin levels in plasma were significantly higher than in control rats. On the contrary, alkalosis inhibited the glucose-stimulated insulin secretion activities in vivo. In spite of low insulin

Submitted Sep. 15, 2013; Accepted Sep. 17, 2013 as EJ13-0380 Released online in J-STAGE as advance publication Oct. 1, 2013

Correspondence to: Fumikazu Okajima, Laboratory of Signal Transduction, Institute for Molecular and Cellular Regulation, Gunma University, 3-39-15 Showa-machi, Maebashi 371-8512, Japan. E-mail: okajima@gunma-u.ac.jp response, however, alkalosis improved glucose tolerance or accelerated glucose utilization. The authors suggested that the change in plasma $\mathrm{pH}$ modifies reciprocally the adrenergic regulation of insulin secretion activities: acidosis enhances $\beta$-adrenergic receptor functions, whereas alkalosis enhances $\alpha$-adrenergic receptor function [2]. However, it is also possible that a change in extracellular $\mathrm{pH}$ modulates insulin secretion activity in pancreatic $\beta$-cells directly rather than indirectly through adrenergic regulation.

There are many reports concerning the effects of extracellular and intracellular $\mathrm{pH}$ on insulin secretion in vitro, but the results are confusing. Insulin secretion caused by high glucose showed a bell-shaped dependence on extracellular $\mathrm{pH}$ with a peak at $\mathrm{pH}$ 7.4: the activity at $\mathrm{pH} 7.7$ and 6.5 was about $50 \%$ of that of $\mathrm{pH}$ 7.4 [4]. A similar bell-shaped response to extracellular $\mathrm{pH}$ was confirmed [5]. Change in the extracellular $\mathrm{pH}$ is accompanied by a change in the intracellular $\mathrm{pH}$, which has been thought to be a critical factor for insulin secretion. Although it is recognized that high glucose induces an increase in the intracellular $\mathrm{pH}[6,7]$, intracellular acidification has been shown to enhance 
glucose-stimulated insulin secretion [8-11]. The inhibition of $\mathrm{K}_{\mathrm{ATP}}$ channels is a possible mechanism of the intracellular acidic $\mathrm{pH}$ effect on insulin secretion [12]; $\mathrm{K}_{\text {ATP }}$ channels have histidine residues involved in either the inhibition or the activation of the activity in response to a change in the intracellular $\mathrm{pH}[13,14]$. The beneficial role of acidic $\mathrm{pH}$ on insulin secretion is supposed to be mainly based on the action of the $\mathrm{Na}^{+} /$ $\mathrm{H}^{+}$exchange blocker: inhibitors of $\mathrm{Na}^{+} / \mathrm{H}^{+}$exchange caused the enhancement of glucose-stimulated insulin secretion in association with a decrease in the intracellular $\mathrm{pH}$. However, the specificity of the $\mathrm{Na}^{+} / \mathrm{H}^{+}$ exchange blocker has recently been questioned [7]. Stiernet et al. showed that dimethyl amiloride (DMA), a classic blocker of $\mathrm{Na}^{+} / \mathrm{H}^{+}$exchange, did not affect intracellular $\mathrm{pH}$ but increased insulin secretion in NHE1 mutant islets, indicating a nonspecific effect. They further showed that, even though intracellular $\mathrm{pH}$ was oppositely changed by a different buffer, i.e., $\mathrm{HCO}_{3}{ }^{-}$ -containing buffer or HEPES buffer without $\mathrm{HCO}_{3}{ }^{-}$, in normal and NHE1 mutant islets, no practical change in glucose-stimulated insulin secretion was observed [7]. These results suggest that intracellular $\mathrm{pH}$ is not causally related to changes in insulin secretion. Thus, the physiological relevance of a change in intracellular $\mathrm{pH}$ to insulin secretion is not established. In any event, previous studies on $\mathrm{pH}$ effects were performed based on the assumption that extracellular $\mathrm{pH}$ changes may affect insulin secretion activity through the changes in intracellular $\mathrm{pH}$. However, recent studies have revealed that there are extracellular proton-sensing mechanisms in cell membranes in many biological systems.

\section{Proton-sensing Receptors}

There are at least two types of proton-sensing mechanisms of cell membranes, which sense extracellular protons and transduce their signal inside the cells. Ionotropic ion channels, such as transient receptor potential V1 (TRPV1) and acid-sensing ion channels (ASICs), have been considered to be proton sensors for pain and nociception because these channels are predominantly expressed on sensory neurons $[15,16]$. Recent studies, however, show that these ion channels are expressed on neurons in the central nervous system and non-neuronal cells and play a role in a wide range of biological systems [15-18]. Another type of proton-sensing receptors is the ovarian cancer $\mathrm{G}$ protein-coupled receptor 1 (OGR1)-family proton-sensing GPCR. While the ion channel type of receptors sense strong acidic $\mathrm{pH}$ of less than 7.0 to $\mathrm{pH}$ 4.0, proton-sensing GPCRs sense neutral and mildly acidic $\mathrm{pH}$ of 7.6 to 6.0 through the histidine residues [19-21]. Thus, proton-sensing GPCRs are expected to regulate the physiological events at neutral $\mathrm{pH}$ as well. In the present review, we discuss the role of proton-sensing receptors, especially focusing on OGR1, a proton-sensing GPCR, in insulin secretion and glucose metabolism in relation to $\mathrm{pH}$ environments. As to the ion channels, we briefly summarize recent observations related to insulin secretion and energy metabolism obtained by using receptor knockout mice.

\section{Proton-sensing ion channels}

TRPV1 is one of 28 isotypes of the TRP superfamily and is activated by a diverse range of chemical and noxious stimuli, including protons [22-24]. Thus, proton is not the sole ligand for TRPV1. TRPV1 senses relatively strong acidic $\mathrm{pH}$ of below 6 through glutamic acid in the extracellular domain of the channel [22], is predominantly expressed on sensory neurons, and mediates pain and nociceptive signals [15]. In pancreatic $\beta$-cells, several types of thermosensitive TRP are expressed and contribute to $\beta$-cell function, including insulin secretion, in response to environmental temperature changes $[25,26]$. TRPV1 is expressed in pancreatic $\beta$-cell lines as well, and capsaicin, a TRPV1 agonist, induces $\mathrm{Ca}^{2+}$ influx and insulin secretion [27, 28]. Capsaicin treatment also increases plasma insulin levels in vivo [27]. However, it is not generally accepted that islets express TRPV1 $[28,29]$. Motter and Ahern have reported that, on a high-fat diet, TRPV1 knockout mice gained significantly less mass and adiposity as compared with wild-type mice [30]. Thus, TRPV1 deficiency protects from diet-induced obesity. Razavi et al. reported that knockout of TRPV1 brought improved glucose tolerance due to enhanced insulin sensitivity [29]. These observations are contrary to the finding that the TRPV1 agonist capsaicin stimulates insulin secretion and beneficial actions on adipose tissues [18]. Thus, capsaicin improves glucose tolerance and insulin sensitivity. The improvement of glucose tolerance is, at least partly, explained by glucagon-like peptide 1 (GLP-1) production, increased adiponectin levels, and decreased plasma levels of free fatty acid, triglycerides, and leptin $[18,31]$. Thus, although loss-offunction and gain-of-function outcomes on TRPV1 are controversial, the ion channel seems to function under normal conditions. It should be remembered, however, 


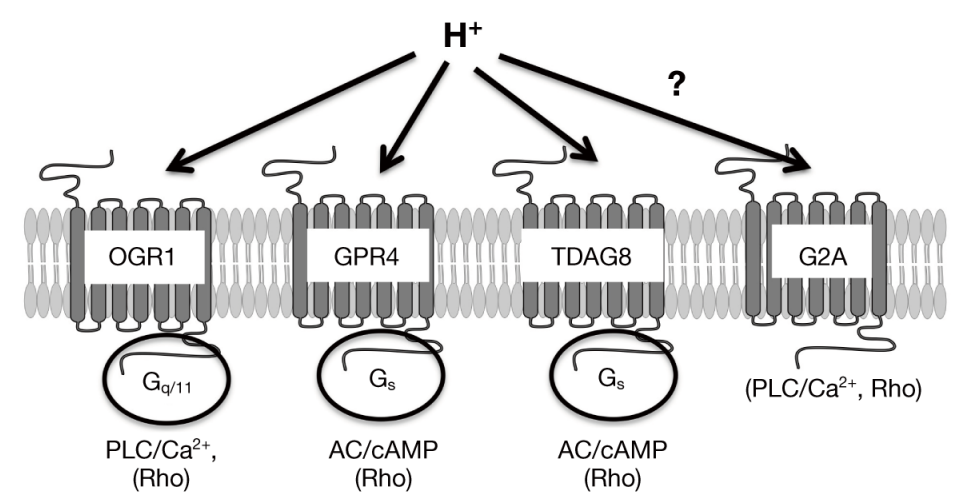

Fig. 1 Signaling mechanisms of proton-sensing GPCRs. Although overexpression of any proton-sensing receptors causes coupling with the Rho signaling pathways through $\mathrm{G}_{12 / 13}$ proteins, OGR1 is usually coupled with $\mathrm{G}_{\mathrm{q} / 11}$ proteins and phospholipase $\mathrm{C}$ (PLC)/ $\mathrm{Ca}^{2+}$ signaling pathways, and TDAG8 and GPR4 are coupled with the $\mathrm{G}_{\mathrm{s}}$ proteins and adenylyl cyclase (AC)/cAMP pathways in native cells. The proton-sensing role of G2A is in question. See the text for more details.

that TRPV1 is a thermosensitive channel, and its thermosensitivity, rather than its proton sensitivity, may contribute to TRPV1's involvement in insulin secretion and its related metabolism [25].

ASICs are another family of proton-sensing channels. Six ASIC subunit proteins, encoded by four genes, have been identified: ASIC1a, ASIC1b, ASIC2a, ASIC2b, ASIC3, and ASIC4. ASICs are voltage-independent channels that mainly conduct $\mathrm{Na}^{+}$[32]. Protons are thought to be the sole physiological ligand for ASICs. Homomeric or heteromeric ASICs exhibit a variety of extracellular $\mathrm{pH}$ sensitivities, ranging from the near physiological $\mathrm{pH}$ of $\sim 7.0$ for ASIC 3 to the severely acidic $\mathrm{pH}$ of $\sim 5.0$ for ASIC2a $[16,33]$. Huang et al. showed that ASIC3 is expressed in adipocytes and that ASIC3 knockout mice were protected against age-dependent glucose tolerance with enhanced insulin sensitivity [34]. Thus, ASIC3 deficiency caused a smaller adipocyte size, improved glucose tolerance and insulin sensitivity, and less mitochondrial loss in white adipose tissue in 27-wk-old mice. However, these changes by ASIC3 deficiency were not observed in 9-wk-old mice. Supporting the phenotypes of ASIC3 knockout mice, an ASIC3-selective blocker, APETx2, improved insulin sensitivity in older mice. Although this report has not proved the phenotype change in ASIC3-deficient mice to be due to the lack of extracellular proton signals, mitochondrial loss in aged mice may cause more acidic microenvironments than in young mice. Indeed, mitochondrial dysfunction is shown to increase lactic acid production through the stimulation of anaerobic glucose metabolism [35] and is associated with insulin resistance in the elderly [36]. As to the pancreatic $\beta$-cell function, expression of ASICs on islets and their involvement in insulin secretion have not been reported.

\section{General information regarding proton-sensing GPCRs}

OGR1 and its related GPCRs were first identified as receptors for sphingosylphosphorylcholine (SPC) and lysophosphatidylcholine (LPC) and have now been demonstrated to sense extracellular $\mathrm{pH}$ or protons, resulting in the stimulation of several types of G proteins and intracellular signaling pathways [see review articles 37-39] (Fig. 1). This family of GPCRs is composed of OGR1, G protein-coupled receptor 4 (GPR4), T cell death-associated gene 8 (TDAG8), and G2 accumulation (G2A). Several histidine residues on the extracellular domain of receptors are identified as sensors of protons [19-21]. Since the pKa of histidine is around 7, certain histidine residues can be protonated in acidic environments, which, in turn, may change the conformation of the receptors to be coupled with G proteins. Although G2A stimulates $\mathrm{Ca}^{2+}$ and Rho signaling pathways when the cells are overexpressed with exogenous G2A [40], whether G2A is functioning as a protonsensing receptor in the cells natively expressing G2A remains established [41]. Overexpression of any proton-sensing receptors causes coupling with the Rho signaling pathways through the $\mathrm{G}_{12 / 13}$ proteins. In native cells, however, OGR1 is coupled with $\mathrm{G}_{\mathrm{q} / 11}$ proteins and phospholipase $\mathrm{C} / \mathrm{Ca}^{2+}$ signaling pathways, and TDAG8 and GPR4 are coupled with the $\mathrm{G}_{\mathrm{s}}$ proteins and adenylyl cyclase/cAMP pathways [37-39] (Fig. 1).

While proton-sensing ion channels are expressed mainly on sensory neurons, proton-sensing GPCRs are expressed not only in neurons but also in a vari- 
ety of cell types. In fact, OGR1 has been reported to be involved in a variety of physiologically important responses to extracellular acidification using a knockdown strategy of the receptor in several types of cells in vitro, e.g., receptor activator of nuclear factor- $\mathrm{KB}$ ligand (RANKL)-induced differentiation in osteoclasts [42], $\mathrm{Ca}^{2+}$ mobilization, cyclooxygenase (COX)-2 induction, and prostaglandin synthesis in osteoblasts [43, 44] and vascular smooth muscle cells [45, 46], and IL-6 and connective tissue growth factor production in airway smooth muscle cells [47-49]. Similarly, TDAG8 has been shown to mediate acidic $\mathrm{pH}$-induced inhibition of apoptosis in eosinophils [50], inflammatory cytokine production in macrophages [51], and $\mathrm{O}_{2}{ }^{-}$production in neutrophils [52]. As for GPR4, this receptor subtype has been reported to mediate acidic-pH-induced stimulation of monocyte adhesion in association with the expression of VCAM-1 [53] and a number of inflammatory genes [54]. In these previous studies, protonsensing GPCRs mediate responses to acidic environments of less than $\mathrm{pH}$ 7.0, which may be attained under inflammatory lesions [39]. Studies using knockout mice have suggested the involvement of host cell OGR1 in tumorigenesis [55] and GPR4 in reduced angiogenesis and tumor growth in vivo as well [56]. In tumors, acidification of less than $\mathrm{pH} 6.0$ has been reported to occur [57]. However, recent studies suggested that the OGR1 family of GPCRs is also involved in the physiological events as well. For example, GPR4 deficiency causes vascular abnormality during development [58] and decreased net acid secretion by the kidney [59], and OGR1 deficiency enhances $\mathrm{pH}$-dependent proton extrusion in proximal tubules form the kidney [60] and changes insulin secretion and insulin sensitivity [61]. In the following sections, we will focus on the role of OGR1 in insulin secretion and $\beta$-cell differentiation. For further information about proton-sensing GPCRs in expression profile, signal transduction mechanism, and their functions other than insulin secretion and $\beta$-cell functions, refer to our review articles [37, 39].

\section{Role of OGR1 in Insulin Secretion and Its Related Metabolism}

\section{In vivo analysis}

In the fasting state, there were no significant differences in the basal plasma insulin and glucose levels before glucose administration between wild-type and $O G R 1^{--}$mice [61]. In order to evaluate the role of
OGR1 on insulin secretion activity and insulin sensitivity, a glucose tolerance test was performed. Insulin levels after glucose administration were significantly lower in OGR1-deficient mice than in WT mice. In spite of the lower insulin level, blood glucose was not appreciably changed or slightly decreased rather than increased by OGR 1 deficiency. To further elucidate the role of OGR1 on glucose metabolism, the effects of OGR1 deficiency on the ability of insulin to decrease blood glucose (insulin sensitivity) and of pyruvate to increase blood glucose (gluconeogenesis activity) were evaluated. OGR1 deficiency enhanced insulin sensitivity but did not change gluconeogenesis activity. The basal plasma glucagon level before glucose injection was significantly lower in OGR1-deficient mice than in WT mice. These results suggest that increased insulin sensitivity to glucose utilization and the lower level of plasma glucagon may explain the masking of the expected hyperglycemia due to impaired insulin secretion in OGR1-deficient mice.

The finding that OGR1 deficiency increases insulin sensitivity means that proton/OGR1 is inhibitory for glucose utilization. Among the tissues and organs involved in glucose metabolism, OGR1 is expressed in adipose tissues but not in liver and skeletal muscle [61]. This reminds us the similarity of the phenotypes of knockout mice of ASIC3, which improve glucose tolerance and insulin sensitivity probably through the change in adipocyte functions [34]. In OGR1-deficient mice, adipose tissue weight is lower than that in WT mice (unpublished results). Thus, proton environments of adipose tissues may regulate adipocyte functions and, finally, whole body glucose utilization activity through OGR1, although the mechanism underlying it remains unknown. With respect to glucose utilization, the inhibitory role of proton/OGR1 in glucose utilization might be related to the finding of Yajima and Ui that alkalosis is stimulatory, whereas acidosis is inhibitory, for glucose utilization $[2,3]$. According to Nakakura et al. [61], OGR1 seems to be inhibitory for glucose utilization at normal or physiological $\mathrm{pH}$ values. If so, alkalosis may reduce OGR1 activity by decreasing proton or ligand concentrations and thereby de-inhibit or stimulate glucose utilization activity or insulin sensitivity.

\section{In vitro analysis of insulin secretion}

Ohta et al. previously reported that glucose-induced insulin secretion exhibited a bell-shaped dependence on extracellular $\mathrm{pH}$ with a peak value at $\mathrm{pH} 7.4$ in rat islets 
[4]. Nakakura et al. also observed a similar bell-shaped dose response curve of protons in mouse islets, although the peak was attained at $\mathrm{pH} 7.0$ to 6.8 [61]. Thus, glucose-stimulated insulin secretion activity was increased from $\mathrm{pH} 8.0$ to 7.0. The role of OGR1 was examined using islets from $O G R 1^{-/}$mice. Insulin secretion activity was inhibited by OGR1 deficiency depending on the extracellular $\mathrm{pH}$; insulin secretion at $\mathrm{pH} 7.4$ to 7.0, but not at 8.0, was significantly suppressed by OGR1 deficiency. Insulin secretion induced by $\mathrm{KCl}$ and tolbutamide was also significantly inhibited even in the absence of high glucose, whereas that induced by several insulin secretagogues, including vasopressin, a GLP-1 receptor agonist, and forskolin, was not suppressed by OGR1 deficiency. Moreover, glucose-induced ATP production was not affected by extracellular $\mathrm{pH}$ and OGR1 deficiency. Thus, glucose metabolism and insulin secretion machinery in islets seem to be unchanged by OGR1 deficiency. The inhibition of insulin secretion was associated with the reduction of a glucose-induced increase in the intracellular $\mathrm{Ca}^{2+}$ concentration mostly depending on $\mathrm{Ca}^{2+}$ influx. The acidic $\mathrm{pH}$-induced insulin secretion was inhibited by YM-254590 and 2-APB, suggesting mediation by $\mathrm{G}_{\mathrm{q} / 11}$ proteins and inositol trisphosphate $\left(\mathrm{InsP}_{3}\right)$ channels. These results suggest that the OGR $1 / \mathrm{G}_{\mathrm{q} / 11}$ protein pathway is activated by extracellular protons existing in the physiological extracellular $\mathrm{pH} 7.4$ and further stimulated by acidification, resulting in the enhancement of insulin secretion in response to high glucose concentrations and $\mathrm{KCl}$. (Fig. 2, the upper side). Thus, the OGR $1 / \mathrm{G}_{\mathrm{q} / 11}$ protein signaling pathway may affect the process(es) of $\mathrm{K}_{\text {ATP }}$ channels and/or voltage-dependent $\mathrm{Ca}^{2+}$ channels; however, the precise mechanism remains unknown [61].

Although extracellular acidic $\mathrm{pH}$-induced insulin secretion is dependent on OGR1, extracellular acidification significantly enhanced the insulin secretion even in OGR1-deficient islets, suggesting the additional mechanism of OGR1-independent $\mathrm{pH}$ action. TDAG8 and GPR4 are expressed in islets; however, the $\mathrm{pH}$-induced enhancement of insulin secretion was not affected by the knockout of these proton-sensing GPCRs (unpublished observation). In islets, neither TRPV1 nor ASIC expression has been reported, although $\beta$-cell lines express TRPV1 and its stimulation causes insulin secretion $[27,28]$. The protonsensing receptor-independent insulin secretion may be related to intracellular acidification as described in the introduction. Intracellular acidification has a potential ability to inhibit $\mathrm{K}_{\mathrm{ATP}}$ channels and, thereby, to induce depolarization of the cells $[12,14]$.

OGR1 deficiency inhibited insulin secretion at neutral $\mathrm{pH} 7.4$, suggesting that OGR 1 is functioning at a physiological $\mathrm{pH}$. One main concern is that OGR1 is practically active at physiological $\mathrm{pH}$ 7.4. Most of previous studies on the role of OGR1 were observed at pathophysiological acidic $\mathrm{pH}$ of less than $\mathrm{pH} 7.0$ [39]. For example, COX-2 expression and $\mathrm{PGE}_{2}$ production in osteoclasts [43] and IL-6 and connective tissue growth factor (CTGF) production in airway smooth muscle cells [47, 48] in response to acidic $\mathrm{pH}$ are observed at $\mathrm{pH} 6.8$ to 6.3. The activation of OGR1 at neutral $\mathrm{pH} 7.4$, however, is not unusual because a remarkable activation of OGR 1 at $\mathrm{pH} 7.4$ is observed in CHO cells and in HEK293 cells, in which OGR1 expression was forced $[19,62]$. These differences in the $\mathrm{pH}$ sensitivity of OGR1 between cell types may simply reflect differences in the expression levels of OGR1 and its coupling efficiency to G proteins and subsequent signaling pathways.

It should be noted, however, that the $\mathrm{pH}$ of insulin secretory granules is maintained at 5.5 to 5.0 with the assistance of vacuolar ATPase (V-ATPase) [63]. Acidic granules are necessary for the processing of insulin and the exocytosis of insulin secretion $[64,65]$. The activity of V-ATPase is regulated by intracellular $\mathrm{pH}$; interestingly, an increase in the intracellular $\mathrm{pH}$ stimulates V-ATP activity, resulting in acidification of the granules [66]. Upon insulin secretion, protons may be released simultaneously into the extracellular space [67]. Thus, we can speculate that a quite high level of protons may stimulate OGR1 in the vicinity of the insulin secretion site (Fig. 2), although this speculation has not been proved.

\section{Role of OGR1 in $\beta$-cell Differentiation and Insulin Synthesis}

Schneider and his colleagues have identified 3,5disubstituted isoxazoles (Isx) by screening a chemical library based on activation of the gene encoding the homeodomain transcription factor, NK2 transcription factor-related, locus $5(\mathrm{NKx} 2.5)$, in mouse pluripotent stem cells [68]. They also found that Isx increased $\left[\mathrm{Ca}^{2+}\right]_{\mathrm{i}}$ in Notch-activated epicardium-derived cells (NECs) in a manner sensitive to inhibitors for phospholipase $\mathrm{C}$ and $\mathrm{InsP}_{3}$ channels, suggesting a $\mathrm{G}_{\mathrm{q} / 11}$ protein mediation [69]. They tested the hypothesis that Isx activate GPCRs by screening a library of recom- 


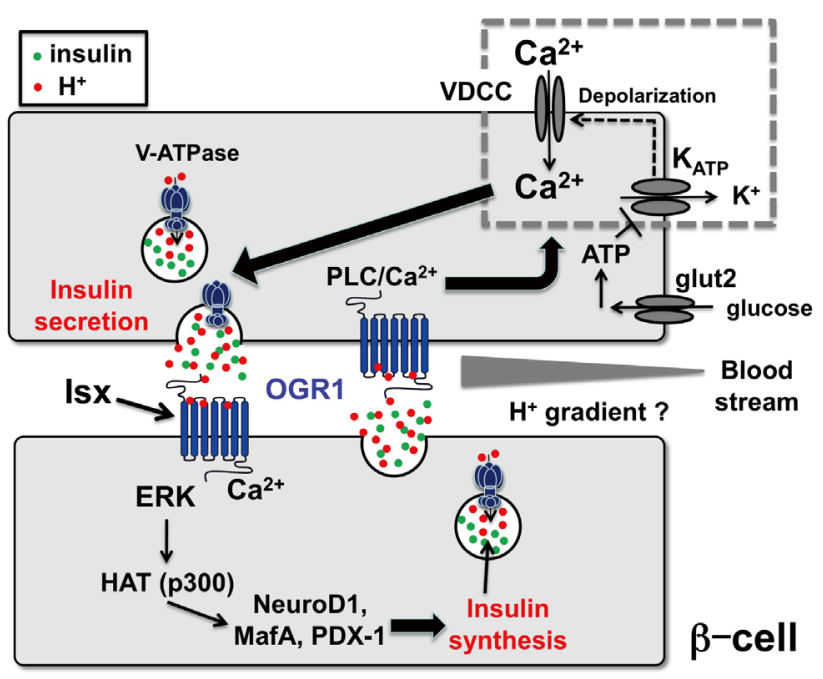

Fig. 2 Postulated roles of OGR1 in insulin secretion and synthesis in pancreatic $\beta$-cells. Glucose-stimulated insulin secretion is thought to be as follows. Glucose is metabolized and finally ATP is generated in $\beta$-cells. This results in closure of the $\mathrm{K}_{\text {ATP }}$ channel and membrane depolarization, which causes the opening of voltage-dependent $\mathrm{Ca}^{2+}$ channel (VDCC) and stimulation of the $\mathrm{Ca}^{2+}$ influx leading to insulin secretion. OGR1 activated by neutral or mildly acidic $\mathrm{pH}(\mathrm{pH} 7.4 \sim 7.0)$ stimulates the process(es) of the $\mathrm{K}_{\text {ATP }}$ channel and/or VDCC and, thereby, enhances glucose-stimulated insulin secretion through the phospholipase C (PLC)/Ca ${ }^{2+}$ signaling pathways (the upper side of the figure). Even at neutral pH, OGR1 can be activated by small molecular compounds (3,5-disubstituted isoxazoles, or Isx) and stimulate insulin synthesis through a mechanism involving extracellular signal-regulated kinase (ERK) and p300 histone acetyltransferase (HAT) (the lower side of the figure). Since the $\mathrm{pH}$ in insulin granules is acidified by vacuolar ATPase (V-ATPase), protons can be released simultaneously with insulin. Thus, even though circulating blood $\mathrm{pH}$ is maintained at 7.4, OGR1 may be activated by high levels of protons in the vicinity of the secretory site. See the text for more details.

binant GPCR-overexpressing cell lines in a functional assay based on $\left[\mathrm{Ca}^{2+}\right]_{\mathrm{i}}$ increase and found that Isx activate only the OGR1-expressing cell line among 158 different GPCR-expressing cell lines [69]. Moreover, knockdown of OGR1 resulted in the attenuation of Isxinduced $\left[\mathrm{Ca}^{2+}\right]_{\mathrm{i}}$ increase, NKx2.5 activity, and biosynthesis and assembly of $\alpha$-actinin pre-sarcomeres [69].

It has already been found that Isx have strong neurogenic activity with the expression of neurogenic transcription factors, including neurogenic differentiation 1 (NeuroD1) [70], which is critical for the development of the pancreas and for insulin production in pancreatic $\beta$-cells. Based on these findings, Dioum et al. characterized Isx actions and their mechanisms in the differentiation of $\beta$-cells and insulin production in human cadaveric islets and MIN6 pancreatic $\beta$-cells [71]. They found that Isx stimulate the expression of insulin and its secretion in response to high glucose, which was associated with several transcription factors important for $\beta$-cell differentiation and insulin synthesis, in primary cultured human islets. Transcription factors included NeuroD1, MafA, PDX-1, paired box gene (Pax) 6, Pax4, Nkx6.1, Nkx2.2, forkhead box A2 (Foxa2), and Ngn3. Isx also stimulate the expression of insulin, glut2, and glucokinase. Similar effects of Isx were observed in MIN6 $\beta$-cells. Thus, Isx stimulated the expression of transcription factors, e.g., NeuroD1 and MafA, and insulin secretion in response to glucose, amino acids, and GLP-1 agonist. Isx caused biphasic activation of ERK1/2 and increased bulk histone acetylation. Although there was little effect on histone deacetylase activity, Isx increased histone acetyl transferase activity in nuclear extracts. Reconstitution assays indicated that Isx increased the activity of the histone acetyl transferase p300 through an ERK1/2-dependent mechanism. The authors concluded that Isx stimulates ERK and histone acetyl transferase activity and, thereby, stimulates several transcription factors critical for $\beta$-cell differentiation through phosphorylation and acetylation [71]. Since a target of Isx is now identified to be OGR1 [69], the results suggest that OGR1 may be involved in the stimulation of intracellular signaling pathways leading to the activation of transcription factors for insulin synthesis and $\beta$-cell differentiation (Fig. 2, the lower side).

They had also found that Isx drive cardiomyogenic and pro-survival transcription programs in myocardial infarction models $[69,72]$ and promote neurogenesis in young mice in vivo [73]. The small molecules also 
inhibit proliferation and induce neuronal gene expression in malignant astrocytes [74]. These results suggest that OGR1 may be involved in cardiomyogenesis and neurogenesis in acidic microenvironments as well. However, the possibility still cannot be ruled out that Isx affect receptors and intracellular signaling molecules other than OGR1. Isx stimulate ERK activity [71] in addition to $\mathrm{Ca}^{2+}$ mobilization [69]. OGR1 is coupled with the $\mathrm{G}_{\mathrm{q} / 11}$ protein and $\mathrm{Ca}^{2+}$ signaling pathway and has been shown to activate ERK at least in airway smooth muscle cells $[47,49]$ and $\mathrm{Ca}^{2+}$ mobilization in several cell types [39]. OGR1 deficiency in mice resulted in no apparent change in the morphology of islets, number of islets, insulin content, or mRNA expression of insulin, glucagon, glut2, Kir6.2, and SUR1 [61], whereas Isx stimulated insulin production and mRNA expression of insulin and glut2 [71]. However, it is not always necessary to obtain opposite results in gain-of-function and lossof-function: $\mathrm{G}_{\mathrm{q} / 11}$ protein-coupled receptors, such as M3 muscarinic receptors, may compensate for the loss of OGR1. As for insulin secretion, the experiment for glucose-stimulated insulin secretion was always carried out at least $24 \mathrm{~h}$ after treatment with Isx [71], whereas acidification effects were observed with simultaneous treatment with glucose for 30 to $60 \mathrm{~min}$ [61]. It would be interesting to examine whether Isx stimulate insulin secretion in a manner sensitive to OGR1, as was case for extracellular acidification. The following two observations are not simply explained by the hypothesis that OGR1 is the sole target of Isx for diverse actions. Isxinduced increase in $\left[\mathrm{Ca}^{2+}\right]_{\mathrm{i}}$ in neural stem cells (NSCs) was completely blocked by nifedipine, an L-type $\mathrm{Ca}^{2+}$ channel blocker and MK801, a specific N-methyl-Daspartic acid (NMDA) receptor antagonist, suggesting $\mathrm{Ca}^{2+}$ influx through $\mathrm{Ca}^{2+}$ channels but not intracellular $\mathrm{Ca}^{2+}$ mobilization through $\mathrm{InsP}_{3}$ [70]. Moreover, acidic $\mathrm{pH}$ failed to stimulate $\mathrm{NKx} 2.5$ activity, whereas Isx stimulated it depending on the extracellular $\mathrm{pH}$ in the NECs [69]. Thus, although there is uncertainty in the specificity of Isx, the small molecules with antidiabetic activity provide a tool not only for exploring islet functions but also for further characterizing the role of OGR1 in biological actions just like capsaicin for TRPV1 functions.

\section{Conclusion and Perspective}

Since extracellular $\mathrm{pH}$ is maintained at around 7.4 under physiological conditions, proton-sensing receptors have been speculated to play a role in pathophys- iological situations, such as ischemia and inflammation, where extracellular $\mathrm{pH}$ reaches below 6.0. Indeed, recent studies have revealed that severe acidosis-induced pain and nociception are mediated by TRPV1 and ASICs, reflecting their predominant expression in sensory neurons; and a wide range of inflammatory responses and related responses are mediated by proton-sensing GPCRs, reflecting their coupling with a variety of intracellular signaling pathways. In addition, proton-sensing receptors, especially proton-sensing OGR1 and ASIC3, sense near-physiological $\mathrm{pH}$ and have been proved to function in physiological events, such as insulin secretion and/or normal glucose metabolism, as described in the present review. Although a TRPV1 agonist capsaicin exerts diverse responses, including glucose metabolism and insulin secretion, whether capsaicin-induced actions are related to and reproduced by extracellular protons remains unknown. TRPV1 is thermosensitive, and its thermosensitivity, rather than its proton sensitivity, may be involved in the actions observed in the knockout mice in vivo.

OGR1 deficiency influenced insulin secretion and glucose metabolism under near-physiological conditions such as glucose tolerance tests. This suggests that proton-sensing OGR1 is activated at physiological $\mathrm{pH}$ 7.4. However, an alternative possibility was presented: OGR1 activation may be accelerated by protons released simultaneously with insulin from secretory granules in which $\mathrm{pH}$ is maintained at 5.5 to 5.0. It would be interesting to extend the hypothesis to neurons, where protons may be released with neurotransmitters into synapses and act on proton-sensing receptors in post-synapses in the nervous system. Proton-sensing GPCRs are expressed in a wide range of cell types, including neurons.

Acidic pH still significantly enhances glucose-stimulated insulin secretion, even in OGR1-deficient islets. This suggests that there is another mechanism, other than OGR1, to regulate insulin secretion with respect to proton environments. It is unlikely, however, that TRPV1, ASICs, and proton-sensing GPCRs other than OGR1 are involved in the secretion on insulin based on their expression profiles and knockout phenotypes. Intracellular $\mathrm{pH}$ change is potentially involved in insulin secretion. As to the change in insulin sensitivity, the roles of proton-sensing receptors are mostly left unclear except for the possible involvement of adipose tissues. 
Finally, it is quite exciting that OGR1 agonists Isx stimulate differentiation not only of pancreatic $\beta$-cells but also of progenitor or stem cells of neurons and cardiomyocytes. At present, however, the possibility cannot be ruled out that Isx may have targets other than OGR1. It is a subject urgently needing to be clarified. Apart from the specificity of the compounds, the finding that Isx stimulate the differentiation of $\beta$-cells and insulin secretion suggests that Isx are lead compounds for improving $\beta$-cell function in diabetics.

\section{Acknowledgments}

This work was supported by grants from Grant-inAid for Scientific Research (B)(21390016), Grant-inAid for Challenging Exploratory Research (22659014, 23659029, 25670617), and Grant-in-Aid for Scientific Research on Innovative Areas (23112503) from the Japan Society for the Promotion of Science (JSPS).

\section{Disclosure}

The authors have no conflict of interest.

\section{References}

1. Ayers P, Dixon C (2012) Simple acid-base tutorial. JPEN J Parenter Enteral Nutr 36: 18-23.

2. Yajima M, Ui M (1975) Carbohydrate metabolism and its response to catecholamines as modified in alkalotic rat. Am J Physiol 228: 1046-1052.

3. Yajima M, Ui M (1975) Hydrocortisone restoration of the $\mathrm{pH}$-dependent metabolic responses to catecholamines. Am J Physiol 228: 1053-1059.

4. Ohta M, Nelson D, Nelson J, Meglasson MD, Erecinska M (1991) Relationships between energy level and insulin secretion in isolated rat islets of Langerhans. A study at various $\mathrm{pH}$ values. Biochem Pharmacol 42: 593-598.

5. Hyder A, Laue C, Schrezenmeir J (2001) Effect of extracellular $\mathrm{pH}$ on insulin secretion and glucose metabolism in neonatal and adult rat pancreatic islets. Acta Diabetol 38: 171-178.

6. Juntti-Berggren L, Arkhammar P, Nilsson T, Rorsman P, Berggren PO (1991) Glucose-induced increase in cytoplasmic $\mathrm{pH}$ in pancreatic beta-cells is mediated by $\mathrm{Na}+$ / $\mathrm{H}+$ exchange, an effect not dependent on protein kinase C. J Biol Chem 266: 23537-23541.

7. Stiernet P, Nenquin M, Moulin P, Jonas JC, Henquin JC (2007) Glucose-induced cytosolic pH changes in betacells and insulin secretion are not causally related: studies in islets lacking the $\mathrm{Na}+\mathrm{H}+$ exchangeR NHE1. $J$ Biol Chem 282: 24538-24546.

8. Best L, Bone EA, Meats JE, Tomlinson S (1988) Is intracellular $\mathrm{pH}$ a coupling factor in nutrient-stimulated pancreatic islets? J Mol Endocrinol 1: 33-38.

9. Gunawardana SC, Sharp GW (2002) Intracellular pH plays a critical role in glucose-induced time-dependent potentiation of insulin release in rat islets. Diabetes 51 : 105-113.

10. Gunawardana SC, Rocheleau JV, Head WS, Piston DW (2004) Nutrient-stimulated insulin secretion in mouse islets is critically dependent on intracellular $\mathrm{pH}$. BMC Endocr Disord 4: 1.
11. Nabe K, Fujimoto S, Shimodahira M, Kominato R, Nishi Y et al. (2006) Diphenylhydantoin suppresses glucose-induced insulin release by decreasing cytoplasmic $\mathrm{H}+$ concentration in pancreatic islets. Endocrinology 147: 2717-2727.

12. Misler S, Gillis K, Tabcharani J (1989) Modulation of gating of a metabolically regulated, ATP-dependent $\mathrm{K}+$ channel by intracellular $\mathrm{pH}$ in $\mathrm{B}$ cells of the pancreatic islet. J Membr Biol 109: 135-143.

13. $\mathrm{Xu} \mathrm{H}$, Cui $\mathrm{N}$, Yang $\mathrm{Z}, \mathrm{Wu}$ J, Giwa LR et al. (2001) Direct activation of cloned K(atp) channels by intracellular acidosis. J Biol Chem 276: 12898-12902.

14. Xu H, Wu J, Cui N, Abdulkadir L, Wang R et al. (2001) Distinct histidine residues control the acid-induced activation and inhibition of the cloned K(ATP) channel. $J$ Biol Chem 276: 38690-38696.

15. Morales-Lazaro SL, Simon SA, Rosenbaum T (2013) The role of endogenous molecules in modulating pain through transient receptor potential vanilloid 1 (TRPV1). J Physiol 591: 3109-3121.

16. Wemmie JA, Taugher RJ, Kreple CJ (2013) Acid-sensing ion channels in pain and disease. Nat Rev Neurosci 14: 461-471.

17. Ho KW, Ward NJ, Calkins DJ (2012) TRPV1: a stress response protein in the central nervous system. Am J Neurodegener Dis 1: 1-14.

18. Zsombok A (2013) Vanilloid receptors--do they have a role in whole body metabolism? Evidence from TRPV1. J Diabetes Complications 27: 287-292.

19. Ludwig MG, Vanek M, Guerini D, Gasser JA, Jones CE et al. (2003) Proton-sensing G-protein-coupled receptors. Nature 425: 93-98.

20. Wang JQ, Kon J, Mogi C, Tobo M, Damirin A et al. (2004) TDAG8 is a proton-sensing and psychosinesensitive G-protein-coupled receptor. J Biol Chem 279: 45626-45633.

21. Liu JP, Nakakura T, Tomura H, Tobo M, Mogi C et 
al. (2010) Each one of certain histidine residues in G-protein-coupled receptor GPR4 is critical for extracellular proton-induced stimulation of multiple G-proteinsignaling pathways. Pharmacol Res 61: 499-505.

22. Tominaga M, Tominaga T (2005) Structure and function of TRPV1. Pflugers Arch 451: 143-150.

23. Banner KH, Igney F, Poll C (2011) TRP channels: emerging targets for respiratory disease. Pharmacol Ther 130: 371-384.

24. Lee LY, Gu Q, Xu F, Hong JL (2013) Acid-sensing by airway afferent nerves. Pulm Pharmacol Ther 26: 491497

25. Uchida K, Tominaga M (2011) The role of thermosensitive TRP (transient receptor potential) channels in insulin secretion. Endocr J 58: 1021-1028.

26. Zhu Z, Luo Z, Ma S, Liu D (2011) TRP channels and their implications in metabolic diseases. Pflugers Arch 461: 211-223.

27. Akiba Y, Kato S, Katsube K, Nakamura M, Takeuchi K et al. (2004) Transient receptor potential vanilloid subfamily 1 expressed in pancreatic islet beta cells modulates insulin secretion in rats. Biochem Biophys Res Commun 321: 219-225.

28. Jabin Fagelskiold A, Kannisto K, Bostrom A, Hadrovic B, Farre C et al. (2012) Insulin-secreting INS-1E cells express functional TRPV1 channels. Islets 4: 56-63.

29. Razavi R, Chan Y, Afifiyan FN, Liu XJ, Wan X et al. (2006) TRPV1+ sensory neurons control beta cell stress and islet inflammation in autoimmune diabetes. Cell 127: 1123-1135.

30. Motter AL, Ahern GP (2008) TRPV1-null mice are protected from diet-induced obesity. FEBS Lett 582: 2257 2262.

31. Wang P, Yan Z, Zhong J, Chen J, Ni Y et al. (2012) Transient receptor potential vanilloid 1 activation enhances gut glucagon-like peptide-1 secretion and improves glucose homeostasis. Diabetes 61: 2155-2165.

32. Lingueglia E (2007) Acid-sensing ion channels in sensory perception. J Biol Chem 282: 17325-17329.

33. Wu WL, Cheng CF, Sun WH, Wong CW, Chen CC (2012) Targeting ASIC3 for pain, anxiety, and insulin resistance. Pharmacol Ther 134: 127-138.

34. Huang SJ, Yang WS, Lin YW, Wang HC, Chen CC (2008) Increase of insulin sensitivity and reversal of age-dependent glucose intolerance with inhibition of ASIC3. Biochem Biophys Res Commun 371: 729-734.

35. Noda M, Yamashita S, Takahashi N, Eto K, Shen LM et al. (2002) Switch to anaerobic glucose metabolism with $\mathrm{NADH}$ accumulation in the beta-cell model of mitochondrial diabetes. Characteristics of betaHC9 cells deficient in mitochondrial DNA transcription. $J$ Biol Chem 277: 41817-41826.

36. Petersen KF, Befroy D, Dufour S, Dziura J, Ariyan C et al. (2003) Mitochondrial dysfunction in the elderly: possible role in insulin resistance. Science 300: 1140-
1142.

37. Tomura H, Mogi C, Sato K, Okajima F (2005) Protonsensing and lysolipid-sensitive G-protein-coupled receptors: a novel type of multi-functional receptors. Cell Signal 17: 1466-1476.

38. Meyer zu Heringdorf D, Jakobs KH (2007) Lysophospholipid receptors: signalling, pharmacology and regulation by lysophospholipid metabolism. Biochim Biophys Acta 1768: 923-940.

39. Okajima F (2013) Regulation of inflammation by extracellular acidification and proton-sensing GPCRs. Cell Signal 25: 2263-2271.

40. Murakami N, Yokomizo T, Okuno T, Shimizu T (2004) G2A is a proton-sensing G-protein-coupled receptor antagonized by lysophosphatidylcholine. J Biol Chem 279: 42484-42491.

41. Radu CG, Nijagal A, McLaughlin J, Wang L, Witte ON (2005) Differential proton sensitivity of related G protein-coupled receptors $\mathrm{T}$ cell death-associated gene 8 and G2A expressed in immune cells. Proc Natl Acad Sci U S A 102: 1632-1637.

42. Komarova SV, Pereverzev A, Shum JW, Sims SM, Dixon SJ (2005) Convergent signaling by acidosis and receptor activator of NF-kappaB ligand (RANKL) on the calcium/calcineurin/NFAT pathway in osteoclasts. Proc Natl Acad Sci U S A 102: 2643-2648.

43. Tomura H, Wang JQ, Liu JP, Komachi M, Damirin A et al. (2008) Cyclooxygenase-2 expression and prostaglandin $\mathrm{E} 2$ production in response to acidic $\mathrm{pH}$ through OGR1 in a human osteoblastic cell line. J Bone Miner Res 23: 1129-1139.

44. Wang J, Sun Y, Tomura H, Okajima F (2012) Ovarian cancer G-protein-coupled receptor 1 induces the expression of the pain mediator prostaglandin E2 in response to an acidic extracellular environment in human osteoblast-like cells. Int J Biochem Cell Biol 44: 1937-1941.

45. Tomura H, Wang JQ, Komachi M, Damirin A, Mogi C et al. (2005) Prostaglandin I(2) production and cAMP accumulation in response to acidic extracellular $\mathrm{pH}$ through OGR1 in human aortic smooth muscle cells. $J$ Biol Chem 280: 34458-34464.

46. Liu JP, Komachi M, Tomura H, Mogi C, Damirin A et al. (2010) Ovarian cancer $\mathrm{G}$ protein-coupled receptor 1-dependent and -independent vascular actions to acidic $\mathrm{pH}$ in human aortic smooth muscle cells. Am J Physiol Heart Circ Physiol 299: H731-742.

47. Ichimonji I, Tomura H, Mogi C, Sato K, Aoki H et al. (2010) Extracellular acidification stimulates IL-6 production and $\mathrm{Ca}(2+)$ mobilization through proton-sensing OGR1 receptors in human airway smooth muscle cells. Am J Physiol Lung Cell Mol Physiol 299: L567-577.

48. Matsuzaki S, Ishizuka T, Yamada H, Kamide Y, Hisada T et al. (2011) Extracellular acidification induces connective tissue growth factor production through protonsensing receptor OGR1 in human airway smooth mus- 
cle cells. Biochem Biophys Res Commun 413: 499-503.

49. Saxena H, Deshpande DA, Tiegs BC, Yan H, Battafarano RJ et al. (2012) The GPCR OGR1 (GPR68) mediates diverse signalling and contraction of airway smooth muscle in response to small reductions in extracellular pH. Br J Pharmacol 166: 981-990.

50. Kottyan LC, Collier AR, Cao KH, Niese KA, Hedgebeth $\mathrm{M}$ et al. (2009) Eosinophil viability is increased by acidic $\mathrm{pH}$ in a cAMP- and GPR65-dependent manner. Blood 114: 2774-2782.

51. Mogi C, Tobo M, Tomura H, Murata N, He XD et al. (2009) Involvement of proton-sensing TDAG8 in extracellular acidification-induced inhibition of proinflammatory cytokine production in peritoneal macrophages. J Immunol 182: 3243-3251.

52. Murata N, Mogi C, Tobo M, Nakakura T, Sato K et al. (2009) Inhibition of superoxide anion production by extracellular acidification in neutrophils. Cell Immunol 259: 21-26.

53. Chen A, Dong L, Leffler NR, Asch AS, Witte ON, Yang LV (2011) Activation of GPR4 by acidosis increases endothelial cell adhesion through the cAMP/Epac pathway. PLoS One 6: e27586.

54. Dong L, Li Z, Leffler NR, Asch AS, Chi JT, Yang LV (2013) Acidosis activation of the proton-sensing GPR4 receptor stimulates vascular endothelial cell inflammatory responses revealed by transcriptome analysis. PLoS One 8: e61991.

55. Yan L, Singh LS, Zhang L, Xu Y (2014) Role of OGR1 in myeloid-derived cells in prostate cancer. Oncogene 33: 157-164.

56. Wyder L, Suply T, Ricoux B, Billy E, Schnell C et al. (2011) Reduced pathological angiogenesis and tumor growth in mice lacking GPR4, a proton sensing receptor. Angiogenesis 14: 533-544.

57. Wike-Hooley JL, Haveman J, Reinhold HS (1984) The relevance of tumour $\mathrm{pH}$ to the treatment of malignant disease. Radiother Oncol 2: 343-366.

58. Yang LV, Radu CG, Roy M, Lee S, McLaughlin J et al. (2007) Vascular abnormalities in mice deficient for the $\mathrm{G}$ protein-coupled receptor GPR4 that functions as a $\mathrm{pH}$ sensor. Mol Cell Biol 27: 1334-1347.

59. Sun X, Yang LV, Tiegs BC, Arend LJ, McGraw DW et al. (2010) Deletion of the $\mathrm{pH}$ sensor GPR4 decreases renal acid excretion. J Am Soc Nephrol 21: 1745-1755.

60. Mohebbi N, Benabbas C, Vidal S, Daryadel A, Bourgeois $S$ et al. (2012) The proton-activated G protein coupled receptor OGR1 acutely regulates the activity of epithelial proton transport proteins. Cell Physiol Biochem 29: 313-324.

61. Nakakura T, Mogi C, Tobo M, Tomura H, Sato K et al. (2012) Deficiency of proton-sensing ovarian cancer G protein-coupled receptor 1 attenuates glucose-stimulated insulin secretion. Endocrinology 153: 4171-4180.

62. Mogi C, Tomura H, Tobo M, Wang JQ, Damirin A et al.
(2005) Sphingosylphosphorylcholine antagonizes proton-sensing ovarian cancer G-protein-coupled receptor 1 (OGR1)-mediated inositol phosphate production and cAMP accumulation. J Pharmacol Sci 99: 160-167.

63. Urbe S, Dittie AS, Tooze SA (1997) pH-dependent processing of secretogranin II by the endopeptidase PC2 in isolated immature secretory granules. Biochem $J 321$ ( Pt 1): 65-74.

64. Sun-Wada GH, Toyomura T, Murata Y, Yamamoto A, Futai M, Wada Y (2006) The a3 isoform of V-ATPase regulates insulin secretion from pancreatic beta-cells. $J$ Cell Sci 119: 4531-4540.

65. Louagie E, Taylor NA, Flamez D, Roebroek AJ, Bright NA et al. (2008) Role of furin in granular acidification in the endocrine pancreas: identification of the V-ATPase subunit Ac45 as a candidate substrate. Proc Natl Acad Sci US A 105: 12319-12324.

66. Dechant R, Binda M, Lee SS, Pelet S, Winderickx J, Peter M (2010) Cytosolic $\mathrm{pH}$ is a second messenger for glucose and regulates the PKA pathway through V-ATPase. EMBO J 29: 2515-2526.

67. Luckie DB, Wilterding JH, Maleszewski JJ, Hobbs EC, Olson LK (2002) Extracellular acidification parallels insulin secretion in INS-1 and HIT-T15 beta-cell lines. Biochem Biophys Res Commun 293: 1168-1173.

68. Sadek H, Hannack B, Choe E, Wang J, Latif S et al. (2008) Cardiogenic small molecules that enhance myocardial repair by stem cells. Proc Natl Acad Sci U S A 105: 6063-6068.

69. Russell JL, Goetsch SC, Aguilar HR, Coe H, Luo X et al. (2012) Regulated expression of $\mathrm{pH}$ sensing $\mathrm{G}$ Protein-coupled receptor-68 identified through chemical biology defines a new drug target for ischemic heart disease. ACS Chem Biol 7: 1077-1083.

70. Schneider JW, Gao Z, Li S, Farooqi M, Tang TS et al. (2008) Small-molecule activation of neuronal cell fate. Nat Chem Biol 4: 408-410.

71. Dioum EM, Osborne JK, Goetsch S, Russell J, Schneider JW, Cobb MH (2011) A small molecule differentiation inducer increases insulin production by pancreatic beta cells. Proc Natl Acad Sci US A 108: 20713-20718.

72. Russell JL, Goetsch SC, Aguilar HR, Frantz DE, Schneider JW (2012) Targeting native adult heart progenitors with cardiogenic small molecules. ACS Chem Biol 7: 1067-1076.

73. Schneider JW, Goetsch SC, Leng X, Ludwig SM, Russell JL et al. (2012) Coupling hippocampal neurogenesis to brain $\mathrm{pH}$ through proneurogenic small molecules that regulate proton sensing $\mathrm{G}$ protein-coupled receptors. ACS Chem Neurosci 3: 557-568.

74. Zhang L, Li P, Hsu T, Aguilar HR, Frantz DE et al. (2011) Small-molecule blocks malignant astrocyte proliferation and induces neuronal gene expression. Differentiation 81: 233-242. 